\title{
Regulatory Documentation Not Other Wise Specified
}

National Cancer Institute

\section{Source}

National Cancer Institute. Regulatory Documentation Not Other Wise Specified. NCI

Thesaurus. Code C115724.

Records of regulatory communications, tracking records, and documents not otherwise specified. 